IRA-International Journal of Management \& Social Sciences

ISSN 2455-2267; Vol.07, Issue 03 (2017)

Pg. no. 509-533

Institute of Research Advances

http://research-advances.org/index.php/RAJMSS

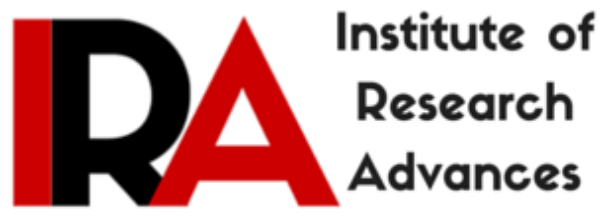

\title{
Loneliness among Shift Workers: An Analysis through Organizational Culture, Interpersonal Communication and Dealing with Emotions
}

\author{
Nandini Sanyal $^{\# 1}$, Aliza Virani ${ }^{2}$, Tina Fernandes ${ }^{3}$ \\ 500016, India. \\ 500016, India. \\ \#corresponding author. \\ Type of Review: Peer Reviewed. \\ DOI: http://dx.doi.org/10.21013/jmss.v7.n3.p12
}

${ }^{1}$ Asst. Prof., Dept. of Psychology, St. Francis College for Women, Begumpet, Hyderabad -

${ }^{2}$ PostGraduate Student, St. Francis College for Women, Begumpet, Hyderabad - 500016, India.

${ }^{3}$ Retd. Head, Dept. of Psychology, St. Francis College for Women, Begumpet, Hyderabad -

\section{How to cite this paper:}

Sanyal, N., Virani, A., Fernandes, T. (2017). Loneliness among Shift Workers: An Analysis through Organizational Culture, Interpersonal Communication and Dealing with Emotions. IRAInternational Journal of Management \& Social Sciences (ISSN 2455-2267), 7(3), 509-533. doi:http://dx.doi.org/10.21013/jmss.v7.n3.p12

(C) Institute of Research Advances

\section{(cc) EY-NC}

This work is licensed under a Creative Commons Attribution-Non Commercial 4.0 International License subject to proper citation to the publication source of the work.

Disclaimer: The scholarly papers as reviewed and published by the Institute of Research Advances (IRA) are the views and opinions of their respective authors and are not the views or opinions of the IRA. The IRA disclaims of any harm or loss caused due to the published content to any party. 


\begin{abstract}
Web Finance Incorporation (2016) explains work shift as a work schedule in which a group of workers rotate through set periods of time. Shift work is well recognized in Customer Service and Hotel Industry. These shift employees often complain of emotional, psychological and physiological difficulties. Against this background, the objective of the present study was to analyze the differences between 160 Day and Night Shift employees (selected through non-probability sampling) working in Customer Service $(n=80)$ and Hotel Industry $(n=80)$.The study also aimed at identifying predictors of Loneliness at Workplace. The Organizational Culture Profile (Pareek, 2011), Interpersonal Communication Inventory (Bienvenu, 1971), Dealing with Emotions (Pareek, 2011) and Loneliness at Workplace (Wright, Burt \& Strongman, 2006) were administered to measure the respective variables. The statistical analysis revealed a significant difference between Customer Service and Hotel Industry employees in terms of trust, authenticity, collaboration, experimentation, rumination and social companionship ( $p<0.05)$. Significant differences in openness, experimentation, coping with feelings, emotional deprivation and social companionship were observed between Day and Night Shift employees ( $p<0.05)$. Results further revealed that among Customer Service employees the major predictors of emotional deprivation were interpersonal communication, proaction and flow and of social companionship were interpersonal communication, proaction, self-expression and openness and among Hotel Industry employees the main predictors of emotional deprivation were proaction, rumination, experimentation, interpersonal communication and perceived acceptance and of social companionship were rumination, experimentation and clarity $(p<0.05)$. The current study highlight the importance of organizational and interpersonal values, companies should promote and uphold in order to build healthy working conditions for their employees eventually culminating into their own success.
\end{abstract}

Keywords: Work Shift, Organizational Culture, Interpersonal Communication, Dealing with Emotions and Loneliness at Workplace.

\title{
INTRODUCTION
}

The working population in the $21^{\text {st }}$ Century is marked by four generations working simultaneously, the Veterans, the Baby Boomers, the Xers and the Nexters (Bolland\& Lopes, 2014). These working generations were introduced to work culture around different social conditions, thus prominent differences can be noted in their work ethics, culture, communication patterns, response to authority and relationships at workplace (London, 2005). Additionally, organizations themselves have evolved from being "Stores" or "Shops" handled by single entrepreneurs to Multi National Corporations with hundreds of employees working under the same top (McMillan, 2002). These changes further indicate changing Organizational Culture, Interpersonal Communication, Dealing with Emotions and ability to cope with Loneliness at Workplace.

Organizational Culture:

Andrew Pettigrew (1979) is recognized to have introduced the concept of organizational culture which he described as an amalgamation of beliefs, identity, rituals and myths. Thus, organizational culture may be defined as "a system of shared meaning held by members that distinguishes one organization from other organizations" (Hofstede, 1980; c.f. Abu-Jarad, Yusof \& Nikbin 2010). Kondalkar (2007) remarks that the purpose of having a culture is served in providing its members an identity, facilitating collective commitment, promoting systems stability and shaping behavior by helping members make sense of their surroundings.

Robbins, Judge, Millett and Boyle (2013) discussed that organizational culture is formed on the basis of the degree to which employees are willing to take risk, exhibit precision and pay attention to detail and 
the management is outcome oriented rather than process or technique oriented, involve the participation of their employees and encourage team work instead of allotting individual tasks. Moreover, Peters, Waterman and Jones (1982), interviewed employees from excellent companies like McDonalds, Boeing, IBM, HP and Bank of America and paralleled their success to strong Organizational Cultures which are fully-functional at multiple levels.

Functionally, organizational culture is said to positively impact organizational performance (AbuJarad, Yusof \& Nikbin, 2010); "sustained superior financial performance" (Barney, 1986), knowledgesharing (Al-Alawi, Al-Marzooqi\& Mohammed, 2007) and organizational effectiveness (Denison \& Mishra, 1995) within an organization.

In terms of the impact of organizational culture on its employees, it was reported that an organization's commitment to creating a safe culture leads to enhanced employee safety perceptions (O'Toole, 2002) and a culture in favor of strong human relations depicts employee satisfaction (Jones, Jimmieson\& Griffiths, 2005). It also has an immense impact on employee retention (Sheridan, 1992), job satisfaction and organizational commitment over the first year and actual turnover after two years (O'Reilly, Chatman \& Caldwell, 1991).

However, organizational culture alone does not support this entire process. Iftikhar, Eriksson and Dickson (2003) reported that the culture of an organization and interpersonal communication between employees is responsible towards the development of a real-time Knowledge Management System. Also transparent communication indicates openness, trust and employee engagement within the organization (Thomas, Zolin \& Hartman, 2009). In light of this discussion the next thrust area of the study incorporates:

Interpersonal Communication:

Communication implies the transfer and understanding of meaning and is of thorough importance to organizations today (Robbins, Judge, Millett \& Boyle, 2013). Thus, interpersonal communication is direct communication "between two or more people in physical proximity in which all the five senses can be utilized and immediate feedback is present" (Graham, 1998). Interpersonal communication may be oral and/or non-verbal communication (Steers \& Black, 1994; Judge et. al., 1997; Kondalkar, 2007).

Having its roots in Social Psychology, interpersonal communication has also left a niche in the organizations. Robbins et al., (2013) elucidate that communication at workplace transpires in three directions Upward (from subordinates to superiors), Downward (from superiors to subordinates) and Lateral (between colleagues at the same level).

Interpersonal communication is the path to meeting one's individual goals (Chaffee \& Berger, 1987) and gratifying one's needs and wants (Rubin \& Rubin, 1992). However, this communication is built due to open-exchange of information between superiors and subordinates (Roberts \&O'Rielly, 1974). Also, one of the early proponents of the communication system - Barnard (1968), maintained that the major task of an executive is communication and it defines the structure, extensiveness and scope of an organization (Henderson, 1997).

In pointing out the importance of other high level management, Bambacas and Patrickson (2008) studied that open communication, trust and ability to listen among Managers and HRs indicated organizational commitment. Additionally, the Nardi and Whittaker (2002) study pointed out, "face-toface communication" is crucial for sustaining social relationships and makes up for the disadvantages of distributed work.

This communication may however, be moderated by how a person deals with his (or) her everyday life situations (specifically work related situations). To this effect, Haggard, Robert and Rose (2011) 
reported that, women often engage in co-rumination at workplace. This study clearly indicated towards the need for social support at workplace and also heads us towards the next thrust area of our current study:

Dealing with Emotions:

Ashkanasy (2003), remarks that the component of emotions has gained a surge in the organizations only in the recent years. Fischer, Shaver and Carnochan (1990) define emotion as "organized, meaningful and generally adaptive action systems. In simpler words, emotions are "Intense feelings directed at something or someone" (Robbins, Judge, Millett, \& Boyle, 2013) and "dealing with" means to take action with respect to something or someone.

Emotions are appraised physically, emotionally and cognitively. In terms of the cognitive experience of emotions one may either experience Rumination or Flow. Nolen-Hoeksema (1998) defines Rumination as "compulsively focused attention on the symptoms of one's distress, and on its possible causes and consequences, as opposed to its solutions." Contrarily, Flow can be understood as complete absorption in what one does (Csikszentmihalyi \& Csikzentmihaly, 1991).

Relevant literature on Rumination was put forth by Donahue, Forest, Vallerand, Lemyre, Crevier Braud and Bergeron (2012) and they reported that rumination at workplace may result due to obsessive passion for work. It was also reported that, employees at workplace, who have work-troubles (either real or imaginary) are often anxious about these troubles and keep mulling over them (Cooper \& Robertson, 2004) and therefore, experience higher levels of stress and burn out (Boren, 2013).

On the other hand, flow in the workplace promotes positive feeling within individuals (Tobert \& Moneta, 2013).Salanova, Bakker and Llorens(2006) indicated that resources lying within the person and in the organization (i.e. self-efficacy beliefs, social support and healthy work climate among others) promote work-related flow. The study also reported that work-related flow enhances individual and organizational resources.

In recent times, the advent of technology (Chen, Mo \& Wang, 2002) has hampered our face to face communication thus causing thorough expression of emotions to take a back seat. With this change, employees may feel lonely at workplace. Against this background the last area explored in this study is: Loneliness at Workplace:

Wright, Burt and Strongman (2006) pointed out that one of the primary issues faced in defining loneliness is its multiple synonyms. However against all odds they define loneliness at workplace as "the distress caused by the perceived lack of good quality interpersonal relationships in a work environment."

Loneliness at Workplace can hinder the achievement of life satisfaction which is a direct indicator of organizational commitment and this was concluded by Yilmaz (2008) in his study of School Principals. Yilmaz (2011) also concluded the Loneliness at Workplace is inversely related to human values. Moreover, loneliness does not only affect one psychologically; Middle-Managers who experienced Loneliness at Workplace reported experiencing strains at work including somatic complaints and social dysfunction (Ren, Chen \& Liang, 2011).

Loneliness at Workplace in the current paper studies the contrasting concepts of emotional deprivation understood as the "frustration of the natural sensitive need for unconditional love" (Baars \& Terruwe, 2002) and social companionship, described as engaging in enjoyable activities with others.

These above mentioned constructs have been studied in the present research on Day Shift and Night Shift employees working in Customer Service and Hotel Industry. Brink and Berndt (2008) explained 
customer service as "identifying and establishing, maintaining and enhancing and, when necessary terminating relationships with customers and other stake holders at a profit so that the objectives of all parties involved are met. This is done by mutual exchange and fulfilling promises." And, Jones and Lockwood (2002) defined the Hotel Industry as, "an operation that provides accommodation and ancillary services to people away from home."

Also, the modern society demands its labor force to be available to their customers throughout the clock. This has led to the creation of shift work more clearly understood as, "a way of organizing daily working hours in which different persons or teams work in succession to cover more than the usual 8 hour day, up to and including the whole 24 hour" (Costa, 2003).

In context of the reviews of the constructs presented above and the organizational areas where the application of these constructs is explored in the following study, some researchers including Fyall (2003) and Ashkanasy (2003) suggested further explorations of these areas to sophisticate their academic scrutiny. Additionally, the globalization of markets has caused the global workforce to make itself available throughout the clock to its counterparts all over the world (Major, Klein, \& Ehrhart, 2002).

Under these conditions healthy work-place relations and work-culture may be seen as providing some relief to employees. In this respect, the current study focuses on analyzing Loneliness in Workplace with respect to Organizational Culture, Dealing with Emotions and Interpersonal Communication among employees working in the Day Shift and Night Shift and those working in Customer Service Relationship and in the Hotel Industry. One other reason that the researcher has undertaken a study of this set of variables is because to the researcher's knowledge no extensive research has been made available on this set of variables. Keeping the present context in view, the objectives of the present study are as follows:

1. To determine whether there is a role of Work Setting (viz., Customer Service and Hotel Industry) and Work Shift (viz., Day Shift and Night Shift) of employees on 8 dimensions of Organizational Culture; Interpersonal Communication and its 11 dimensions; 2 dimensions of Rumination: Dealing with Feelings; and 2 dimensions of Loneliness at Workplace.

2. To determine whether the 8 dimensions of Organizational Culture; Interpersonal Communication and its 11 dimensions and the 2 dimensions of Rumination: Dealing with Feelings predict the 2 dimensions of Loneliness at Workplace.

\section{METHOD}

\section{Research Design}

The present study adopts a between group design to study the difference between Day and Night Shift employees working in Customer Service and Hostel Industry with respect to Organizational Culture, measured in terms of its 8 dimensions (viz., Openness, Confrontation, Trust, Authenticity, Proaction, Autonomy, Collaboration and Experimentation), Interpersonal Communication and its 11 dimensions (viz., Self Disclosure, Awareness, Evaluation and Acceptance of Feedback, Self Expression, Attention, Coping with Feelings, Clarity, Avoidance, Dominance, Handling Differences and Perceived Acceptance), Dealing with Emotions, measured in terms of its 2 dimensions (viz., Rumination and Flow) and Loneliness at Workplace, also measured in terms of its 2 dimensions (viz., Social Companionship and Emotional Deprivation). The present study also employs a correlational design to assess if Organizational Culture, Interpersonal Communication and Dealing with Emotions predict Loneliness at Workplace in Day and Night Shift Customer Service and Hotel Industry Employees. 


\section{Sample}

A Non-Probability Purposive Sampling technique was used to select 180 Day and Night Shift employees (aged 20 - 35 years) working in Customer Service and Hospitality Industry. Among them 80 employees were working in Customer Service (40 Day Shift and 40 Night Shift) and 80 employees were working in Hotel Industry (40 Day Shift and 40 Night Shift). Employees with a minimum experience of 1 year in that particular industry and with a minimum experience of 6 months in that particular shift were included in the sample. Employees working in the front desk, housekeeping and food and beverages (service) departments in the hotel industry and those engaged in either call or email interactions with customers in the Customer Service Sector were considered for the present study.

\section{Instruments}

The Study employs the following five instruments:

\section{Information Schedule}

The participants were asked to fill an Information Schedule which included their general demographic details consisting of their age, sex, gender, state of residence, education completed, family type, family income and other details. The demographic sheet also included demographic details specific to the present study regarding the participants' work setting, number of years in the present industry, shift timing and number of years in the present shift.

\section{Organizational Culture Profile (OCTAPACE)}

The Organizational Culture Profile (OCTAPACE) (2011) was developed by UdaiPareek. It measures the system of shared meaning held by members within an Organization. The scale demonstrates a Split Half Reliability $=0.81$ and an Alpha Coefficient $=0.90$. The scale consists of 40 items that gives the profile of an organization's ethos in eight values (represented by the acronym OCTAPACE). These are openness, confrontation, trust, authenticity, proaction, autonomy, collaboration and experimentation.

The scale consists of two parts. In Part I values are stated in items 1 to 24 (three statements for each value). These statements are marked on a four - point scale, where High Value (scores 4), Fairly High Value (scores 3), Low Value (Scores 2) and Very Low Value (Scores 1) to mark how much each item is valued in their organization. Part II consists of sixteen statements on beliefs, 2 statements representing each value. The participant checks on a four - point scale, where Widely (Scores 4), Fairly Widely (Scores 3), Some Persons (Scores 2) and Few Persons or None (Scores 1) expressing to what extent each of the belief is shared in their organization. The following item numbers: 12, 22, 25, 26, 28, 30, 31, 35 and 40 are reverse scored. The scoring is done by adding the scores of each value (dimension) across the row. The scores on each value range between scores of 5 to 20 .

\section{Interpersonal Communication Inventory}

Interpersonal Communication Inventory (1976) is a 40-item scale which measures interpersonal components of an individual to be an effective Communicator. It was developed by Millard J. Bienvenu. The items on the scale recorded a factor loading ranging 0.36 to 0.80 . The scale has a Test-Retest Reliability $=0.86$ and Split Half Reliability $=0.87$. It measures the respondent's ability on 11 dimensions, namely, self disclosure, awareness, evaluation and acceptance of feedback, self expression, attention, coping with feelings, clarity, avoidance, dominance, handling differences and perceived acceptance.

The respondent answers the items on a 'Yes', 'No' or 'Sometimes' Scale; where 'Yes' is to be used when the item is seen as happening 'most of the time (or) usually', 'No' is to be used when the item is 
seen as happening 'seldom (or) never' and 'Sometimes' when the answer to the item is not a definite 'Yes' or 'No'. The following items 1, 2, 5, 7, 9, 11, 12, 14, 15, 19, 20, 23, 26, 29, 31, 32, 35, 36, 38 and 40 were scored on a scale of 3,0 and 2 . Items $3,4,6,8,10,13,16,17,18,21,22,24,25,27,28,30,33$, 34,37 and 39 were scored on a scale of 0,3 and 1 .

\section{Dealing with Emotions}

Dealing with Emotions (Pareek, 2011) is a 7-item scale that measures the probable cognitive action an individual may take with respect to his/her emotions. This cognitive appraisal aims to measure whether the respondent recalls misfortunes, miseries, failures or bad experiences while sitting alone or in discussion with several people. These recollections are labeled under the dimension of Rumination. Another possible cognitive appraisal may appear when the respondent indulges in relieving good experiences and enjoys such recollection; which is measured in terms of the dimension of Flow. The scale demonstrated a Guttman Split Half Index $=54$, Equal and Unequal Length Split Half Brown Indices $=55$ and Guttman Lambada ranged from 44 to 74 . The first three items are scored on a Yes or No Scale, where Yes (Scores 4) and No (scores 0). Items four to Seven are scored on a five point scale where Frequently (scores 4), Often (Scores 3), Sometimes (Scores 2), Occasionally (Scores 1), Almost Never (Scores 0).

\section{Loneliness at Workplace}

The Loneliness at Workplace Scale (Wright, Burt \& Strongman, 2006) is a 16-item scale that measures the respondent's relationships with colleagues, managers and subordinates at work place. The Scale was divided into two parts. Part A (items 1 to 9) measures emotional deprivation. Part B (items 10 to 16) measures social companionship. The items on the scale were measures on a 7-point likert scale with the responses ranging from Strongly Disagree (score 1), Slightly Disagree (Score 2), Disagree (Score 3), Neutral (Score 4), Agree (Score 5), Slightly Agree (Score 6) and Strongly Agree (Score 7). Items 5, 6, 10, 11, 12, 14, 15 and 16 are reverse scored. The scale has a Cronbach Alpha Co-efficient for Emotional Deprivation $=0.93$ and Cronbach Alpha Co-efficient for Social Companionship $=0.87$. Item-Total Correlations range from 0.45 to 0.78 .

\section{Procedure}

After selecting the measures, the potential organizations were identified and approached. Permission from these organizations was sought. Once permission was granted, employees in the organization were approached and a rapport was established. During this visit, these employees were briefed about the study and those who consented to participate signed the Informed Consent Sheet. Later a Demographic Sheet regarding their details was filled by the participants. On the next visit, these employees (participants) were approached and the questionnaires were handed over to them. Written and oral instructions were given to the participants regarding answering the questionnaire. They were asked to seek clarifications for any doubts. The participants were informed that there is no time limit; however, they were asked to try and complete the questionnaires in approximately $40-45$ minutes. The Participants answered the Questionnaires. The collected data was later analyzed using descriptive and inferential statistics and conclusions were drawn.

\section{RESULTS}

Table 1 - Indicates the Means, Standard Deviations, Two-Way ANOVA and Interaction Effect with Work Setting and Work Shift as the IVs and dimensions of Organizational Culture, Interpersonal Communication and its dimensions, dimensions of Dealing with Emotions and dimensions of Loneliness at Workplace as the DVs. 


\begin{tabular}{|c|c|c|c|c|c|c|c|}
\hline \multirow[t]{2}{*}{ Variables } & \multicolumn{3}{|c|}{ Work Setting } & \multicolumn{3}{|c|}{ Work Shift } & \multirow{2}{*}{$\begin{array}{c}\text { Interaction Effect } \\
\text { (Work Setting * } \\
\text { Work Shift) }\end{array}$} \\
\hline & $\begin{array}{c}\text { Customer } \\
\text { Sevice } \\
M \\
(S D)\end{array}$ & $\begin{array}{c}\text { Hotel } \\
\text { Industry } \\
M \\
(S D)\end{array}$ & $F$ & $\begin{array}{c}\text { Day } \\
\text { Shift } \\
M \\
(S D)\end{array}$ & $\begin{array}{c}\text { Night } \\
\text { Shift } \\
M \\
(S D)\end{array}$ & $F$ & \\
\hline Openness & $\begin{array}{c}13.64 \\
(3.107)\end{array}$ & $\begin{array}{c}14.36 \\
(2.935)\end{array}$ & 2.459 & $\begin{array}{l}14.78 \\
(2.93)\end{array}$ & $\begin{array}{c}13.23 \\
(2.947)\end{array}$ & $11.24 * *$ & 1.547 \\
\hline Confrontation & $\begin{array}{l}13.55 \\
(3.23)\end{array}$ & $\begin{array}{c}14.15 \\
(2.408)\end{array}$ & 1.778 & $\begin{array}{l}13.975 \\
(2.765)\end{array}$ & $\begin{array}{l}13.73 \\
(2.95)\end{array}$ & 0.309 & 1.778 \\
\hline Trust & $\begin{array}{c}13.25 \\
(2.749)\end{array}$ & $\begin{array}{c}14.23 \\
(2.261)\end{array}$ & $6.029^{*}$ & $\begin{array}{c}14.06 \\
(2.645)\end{array}$ & $\begin{array}{c}13.41 \\
(2.438)\end{array}$ & 2.679 & 0.016 \\
\hline Authenticity & $\begin{array}{l}12.41 \\
(2.45)\end{array}$ & $\begin{array}{l}12.56 \\
(2.42)\end{array}$ & $0.15 * *$ & $\begin{array}{l}12.75 \\
(2.21)\end{array}$ & $\begin{array}{l}12.23 \\
(2.61)\end{array}$ & 1.874 & $1.09 *$ \\
\hline Proaction & $\begin{array}{c}14.83 \\
(3.058)\end{array}$ & $\begin{array}{c}15.98 \\
(2.193)\end{array}$ & 7.504 & $\begin{array}{l}15.65 \\
(2.96)\end{array}$ & $\begin{array}{l}15.16 \\
(2.41)\end{array}$ & 1.378 & 4.830 \\
\hline Autonomy & $\begin{array}{l}12.41 \\
(2.27)\end{array}$ & $\begin{array}{l}12.63 \\
(2.21)\end{array}$ & .362 & $\begin{array}{c}12.5 \\
(2.46)\end{array}$ & $\begin{array}{l}12.54 \\
(2.00)\end{array}$ & .011 & 3.260 \\
\hline Collaboration & $\begin{array}{c}13.45 \\
(2.751)\end{array}$ & $\begin{array}{l}14.59 \\
(2.45)\end{array}$ & $7.70 * *$ & $\begin{array}{l}14.36 \\
(2.87)\end{array}$ & $\begin{array}{l}13.68 \\
(2.40)\end{array}$ & 2.812 & 0.492 \\
\hline Experimentation & $\begin{array}{l}12.93 \\
(3.52)\end{array}$ & $\begin{array}{l}14.01 \\
(2.57)\end{array}$ & $5.06^{*}$ & $\begin{array}{c}13.95 \\
(3.039)\end{array}$ & $\begin{array}{l}12.99 \\
(3.14)\end{array}$ & $3.96^{*}$ & 0.193 \\
\hline Interpersonal Communication & 65.24 & 65.5 & .016 & 66.29 & 64.45 & .774 & $3.97 * *$ \\
\hline Self Disclosure & $\begin{array}{c}10.5 \\
(3.60)\end{array}$ & $\begin{array}{c}9.86 \\
(3.53)\end{array}$ & 1.295 & $\begin{array}{c}10.5 \\
(3.38)\end{array}$ & $\begin{array}{c}9.86 \\
(3.74)\end{array}$ & 1.295 & 2.801 \\
\hline Awareness & 12.01 & 11.43 & 1.076 & 11.98 & 11.46 & .819 & 0.024 \\
\hline $\begin{array}{l}\text { Evaluation and Acceptance of } \\
\text { Feedback }\end{array}$ & $\begin{array}{c}7.9 \\
(3.08)\end{array}$ & $\begin{array}{l}7.89 \\
(2.61)\end{array}$ & .001 & $\begin{array}{l}8.01 \\
(2.91)\end{array}$ & $\begin{array}{l}7.78 \\
(2.80)\end{array}$ & .276 & 1.411 \\
\hline Self Expression & $\begin{array}{c}8.08 \\
(3.041)\end{array}$ & $\begin{array}{c}8.38 \\
(3.61)\end{array}$ & .322 & $\begin{array}{l}8.26 \\
(3.27)\end{array}$ & $\begin{array}{l}8.19 \\
(3.39)\end{array}$ & .020 & 0.181 \\
\hline Attention & $\begin{array}{c}2.91 \\
(1.87)\end{array}$ & $\begin{array}{l}3.29 \\
(1.79)\end{array}$ & 1.689 & $\begin{array}{l}3.19 \\
(1.83)\end{array}$ & $\begin{array}{c}3.01 \\
(1.85)\end{array}$ & .368 & 3.003 \\
\hline
\end{tabular}

(Continued) 


\begin{tabular}{|c|c|c|c|c|c|c|c|}
\hline \multirow[t]{2}{*}{ Variables } & \multicolumn{3}{|c|}{ Work Setting } & \multicolumn{3}{|c|}{ Work Shift } & \multirow{2}{*}{$\begin{array}{c}\text { Interaction Effect } \\
\text { (Work Setting * } \\
\text { Work Shift) }\end{array}$} \\
\hline & $\begin{array}{c}\text { Customer } \\
\text { Sevice } \\
M \\
(S D)\end{array}$ & $\begin{array}{c}\text { Hotel } \\
\text { Industry } \\
M \\
(S D)\end{array}$ & $F$ & $\begin{array}{c}\text { Day } \\
\text { Shift } \\
M \\
(S D)\end{array}$ & $\begin{array}{c}\text { Night } \\
\text { Shift } \\
M \\
(S D)\end{array}$ & $F$ & \\
\hline Coping with Feelings & $\begin{array}{c}4.31 \\
(2.27)\end{array}$ & $\begin{array}{c}4.39 \\
(2.17)\end{array}$ & .049 & $\begin{array}{c}3.79 \\
(2.07)\end{array}$ & $\begin{array}{c}4.91 \\
(2.22)\end{array}$ & $11.00^{* *}$ & 2.631 \\
\hline Clarity & $\begin{array}{c}5.01 \\
(2.48)\end{array}$ & $\begin{array}{c}5.18 \\
(2.35)\end{array}$ & .186 & $\begin{array}{c}5.46 \\
(2.04)\end{array}$ & $\begin{array}{c}4.73 \\
(2.70)\end{array}$ & 3.832 & 2.643 \\
\hline Avoidance & $\begin{array}{c}5.05 \\
(2.44)\end{array}$ & $\begin{array}{c}5.69 \\
(2.30)\end{array}$ & 2.931 & $\begin{array}{c}5.44 \\
(2.43)\end{array}$ & $\begin{array}{c}5.30 \\
(2.35)\end{array}$ & .136 & 3.408 \\
\hline Dominance & $\begin{array}{c}3.09 \\
(1.66)\end{array}$ & $\begin{array}{c}3.08 \\
(1.90)\end{array}$ & .002 & $\begin{array}{c}3.1 \\
(1.75)\end{array}$ & $\begin{array}{c}3.06 \\
(1.82)\end{array}$ & .018 & 0.329 \\
\hline Handling Differences & $\begin{array}{c}3.2 \\
(2.00)\end{array}$ & $\begin{array}{c}3.04 \\
(1.82)\end{array}$ & .287 & $\begin{array}{c}3.11 \\
(1.79)\end{array}$ & $\begin{array}{c}3.13 \\
(2.03)\end{array}$ & .002 & 1.633 \\
\hline Perceived Acceptance & $\begin{array}{c}3.18 \\
(1.81)\end{array}$ & $\begin{array}{c}3.3 \\
(1.96)\end{array}$ & .175 & $\begin{array}{c}3.45 \\
(1.79)\end{array}$ & $\begin{array}{c}3.03 \\
(1.96)\end{array}$ & 2.024 & 0.063 \\
\hline Rumination & $\begin{array}{c}57.53 \\
(14.75)\end{array}$ & $\begin{array}{c}52.48 \\
(10.54)\end{array}$ & $6.13^{*}$ & $\begin{array}{l}55.005 \\
(11.89)\end{array}$ & $\begin{array}{c}55.00 \\
(14.15)\end{array}$ & 0.000 & 0.007 \\
\hline Flow & $\begin{array}{c}58.52 \\
(16.78)\end{array}$ & $\begin{array}{c}58.76 \\
(13.91)\end{array}$ & .010 & $\begin{array}{c}59.90 \\
(13.56)\end{array}$ & $\begin{array}{c}57.37 \\
(16.97)\end{array}$ & 1.083 & 0.859 \\
\hline Emotional Deprivation & $\begin{array}{l}29.86 \\
(9.15)\end{array}$ & $\begin{array}{l}29.38 \\
(9.53)\end{array}$ & .115 & $\begin{array}{l}28.13 \\
(9.46)\end{array}$ & $\begin{array}{l}31.11 \\
(8.96)\end{array}$ & $4.32 * *$ & $6.50 * *$ \\
\hline Social Companionship & $\begin{array}{l}31.43 \\
(8.92)\end{array}$ & $\begin{array}{l}28.68 \\
(8.09)\end{array}$ & $4.34 * *$ & $\begin{array}{l}28.66 \\
(9.59)\end{array}$ & $\begin{array}{l}31.44 \\
(7.28)\end{array}$ & $4.42 * *$ & $3.954 * *$ \\
\hline
\end{tabular}

Note: $* * \mathrm{p}<0.01 ; * \mathrm{p}<0.05$

$\mathrm{df}=1$

$n=160$

Table 1 indicated that there was a significant difference between employees working in the Day Shift and employees working in the Night Shift with respect to the openness dimension of Organizational Culture $(\mathrm{F}=11.24, \mathrm{p}<0.01)$. As is evident from the above presented Table, employees in the Day Shift scored a higher mean $(M=14.78)$ than employees working in the Night Shift $(M=13.23)$. In other words, employees in the Day Shift view their Organizational Culture as being more favorable in encouraging spontaneous expression of feelings and thoughts and also permitting employees to share these without defensiveness.

The trust dimension of Organizational Culture as presented in Table 1, illustrated a significant difference between employees working in Customer Service and those serving in Hotel Industry ( $\mathrm{F}=$ $6.029, \mathrm{p}<0.05)$. As is evident from the Table, employees working in Hotel Industry scored higher $(\mathrm{M}=14.23)$, than employees working in Customer Service $(\mathrm{M}=13.25)$. In other words, employees working in Hotel Industry viewed their Organizational Culture as being more favorable in maintaining confidentiality and honoring mutual commitment than employees working in Customer Service.

Analysis revealed that, the authenticity dimension of Organizational Culture presented a significant difference between employees working in Customer Service and those serving in Hotel Industry $(\mathrm{F}=0.15$, 
$\mathrm{p}$ <0.01). As is evident from the Table, employees working in Hotel Industry scored a higher mean $(M=12.56)$, when compared to the employees working in Customer Service $(M=12.41)$. In other words, employees working in Hotel Industry viewed the Organizational Culture of their organization in terms of taking initiative, preplanning and taking necessary preventive measures than employees working in Customer Service.

It can be seen further that, there was a significant difference between employees working in Customer Service and Hotel Industry on the collaboration dimension of Organizational Culture $(\mathrm{F}=7.70, \mathrm{p}<0.01)$. As Table 1 indicated, employees working in Hotel Industry scored higher $(\mathrm{M}=14.59)$, than employees working in Customer Service (M=13.45). In other words, employees working in Hotel Industry viewed their organization as upholding an Organizational Culture that encourages giving help to and asking for help from others.

Another dimension of Organizational Culture that illustrated a significant difference between employees working in Customer Service and Hotel Industry is experimentation $(\mathrm{F}=5.06, \mathrm{p}<0.05)$. Employees working in Day Shift and Night shift also showed a significant difference on this dimension $(\mathrm{F}=3.96, \mathrm{p}<0.05)$. As is evident, employees working in the Hotel Industry $(\mathrm{M}=14.01)$, especially employees working in the Day Shift $(\mathrm{M}=13.95)$ scored a higher mean in comparison to the employees working in the Customer Service $(M=12.93)$ and also those working in the Night Shift $(M=12.99)$. In other words it can be stated that, employees working in the Day Shift in the Hotel Industry identify their Organizational Culture as using and encouraging innovative approaches to solve problems, taking a fresh look at things and encouraging creativity.

Apart from the dimensions of Organizational Culture, the coping with feelings dimension of Interpersonal Communication demonstrated a significant difference between employees working in the Day Shift and Night Shift $(\mathrm{F}=11.00, \mathrm{p}<0.01)$. Also it can be interpreted that employees working in the Night Shift have a higher score $(M=4.91)$ than employees working in the Day Shift $(M=3.79)$. In other words it can be stated that employees working in the Night Shift viewed themselves as being truthful in expressing anger, faults and admitting error.

The rumination dimension of Dealing with Emotions demonstrated a significant difference between the employees working in the Customer Service and the Hotel Industry $(\mathrm{F}=6.13, \mathrm{p}<0.05)$. As is manifested from Table 1, the employees working in the Customer Service experienced a higher sense of rumination $(\mathrm{M}=57.53)$ when compared to employees working in the Hotel industry $(\mathrm{M}=52.48)$. In other words, it can be interpreted that employees in Customer Service, focus their attention on symptoms of their distress, their cause and consequences rather than focusing on the possible solution.

On the scale of Loneliness at Workplace, the dimension of emotional deprivation, displayed a significant difference between employees working in the Day Shift and employees working in the Night Shift $(\mathrm{F}=4.32$, $\mathrm{p}<0.01)$. Employees working in the Night Shift scored higher $(\mathrm{M}=31.11)$ when compared to employees working in the Day Shift $(\mathrm{M}=28.13)$. In other words it can be said that employees working in the Night Shift experienced a sense of distance from their colleagues at workplace.

Table 1 also indicated that there was a significant difference between Customer Service and Hotel Industry employees on the Loneliness at Workplace dimension of social companionship ( $\mathrm{F}=4.34$, $\mathrm{p}<0.01)$. There was also a significant difference between employees working in the Day Shift and the employees working in the Night Shit on this dimension $(\mathrm{F}=4.42, \mathrm{p}<0.01)$. The employees working in the Customer Service $(M=31.43)$ especially those working in the Night Shift $(M=31.44)$ scored a higher mean when compared to employees working in the Hotel Industry $(\mathrm{M}=28.68)$ and those working in the Day Shift $(M=28.66)$. In other words it can be said, that employees working in the Night Shift in the Customer Service sector often seek camaraderie or friendship at workplace. 
The Table also indicated a significant interaction effect between Work Setting (viz., Customer Service and Hotel Industry) and Work Shift (viz., Day Shift and Day Night) on the authenticity dimension of Organizational Culture $(\mathrm{F}=1.09, \mathrm{p}<0.05)$, Interpersonal Communication $(\mathrm{F}=3.97, \mathrm{p}<0.01)$ and the emotional deprivation $(\mathrm{F}=6.50, \mathrm{p}>0.01)$ and social companionship $(\mathrm{F}=3.954, \mathrm{p}<0.01)$ dimensions of Loneliness at Workplace.

From the above presented Table, it can be concluded that there was no significant difference between Work Setting (viz. Business Processing Outsourcing and Hospitality) on the Organizational Culture Dimensions of openness, confrontation, proaction and autonomy; Interpersonal Communication and the dimensions of self disclosure, awareness, evaluation and acceptance of feedback, self expression, attention, coping with feelings, clarity, avoidance, dominance, handling differences and perceived acceptance, Dealing with Emotions dimension of flow and Loneliness at Workplace dimension of emotional deprivation $(\mathrm{p}>0.05)$.

In terms of Work Shift (viz., Day Shift and Night Shift), no significant difference was observed in terms of the Organizational Culture dimensions of confrontation, trust, authenticity, proaction, autonomy and collaboration; Interpersonal Communication and the dimensions of self disclosure, awareness, evaluation and acceptance of feedback, self expression, attention, clarity, avoidance, dominance, handling differences and perceived acceptance; and the Dealing with Emotions dimensions of rumination and flow $(\mathrm{p}>0.05)$.

A final interpretation that can be drawn from Table 1 is that there was no significant interaction effect between Work Setting and Work Shift was observed on the Organizational Culture dimensions of openness, confrontation, trust, authenticity, proaction and autonomy; collaboration and experimentation, the Interpersonal Communication dimensions of self disclosure, awareness, evaluation and acceptance of feedback, self expression, attention, coping with feelings, clarity, avoidance, dominance, handling differences and perceived acceptance and Dealing with Emotion dimensions of rumination and flow $(\mathrm{p}>0.05)$.

Table 2 - Summary of stepwise regression, showing predictors for dimensions of Loneliness at Workplace: Emotional deprivation and Social companionship in Customer Service $(n=80)$.

\begin{tabular}{ccccccccccccc}
\hline Criterion Variable & & \multicolumn{3}{c}{$\beta$} & & & \multicolumn{3}{c}{ Changes in R $^{2}$} & \multicolumn{3}{c}{ Total Adjusted R $^{2}$} \\
& $\begin{array}{c}\text { Interpersonal } \\
\text { Communication }\end{array}$ & Proaction & Flow & $\begin{array}{c}\text { Self } \\
\text { Expression }\end{array}$ & $\begin{array}{c}\text { Openness } \\
\text { Interpersonal } \\
\text { Communication }\end{array}$ & $\begin{array}{c}\text { Proaction } \\
\text { Flow } \\
\text { Expression }\end{array}$ & Openness \\
\hline $\begin{array}{c}\text { Emotional } \\
\text { Deprivation }\end{array}$ & $(-) 0.428^{* *}$ & $0.23^{*}$ & $0.204^{*}$ & NS & NS & $0.183^{* *}$ & $0.051^{*}$ & $0.041^{*}$ & NS & NS & $0.247^{*}$ \\
$\begin{array}{c}\text { Social } \\
\text { Companionship }\end{array}$ & $(-) 0.467^{* *}$ & $(-) 0.231^{*}$ & NS & $0.314^{*}$ & $0.21^{*}$ & $0.218^{* *}$ & $0.042^{*}$ & NS & $0.059^{*}$ & $0.035^{*}$ & $0.319^{*}$ \\
\hline
\end{tabular}

Note: $* * \mathrm{p}<0.01 ; * \mathrm{p}<0.05, \mathrm{~N}=80$

Table 2 indicated a summary of the regression analyses for the Loneliness at Workplace dimensions of emotional deprivation and social companionship. Emotional deprivation in employees of Customer Service was predicted by Interpersonal Communication, proaction dimension of Organizational Culture and flow dimension of Dealing with Emotions. Social companionship in employees of Customer Service was predicted by Interpersonal Communication, proaction dimension of Organizational Culture, self expression dimension of Interpersonal Communication and openness dimension of Organizational Culture. Tables 3 and 4 represent these dimensions in details 
Table 3 - Stepwise regression analyses showing various models predicting Emotional deprivation in employees working in Customer Service $(n=80)$.

\begin{tabular}{lccc}
\hline \multicolumn{1}{c}{ Predictor } & $\mathrm{R}$ & $\Delta \mathrm{R}^{2}$ & $\beta$ \\
\hline & $\begin{array}{l}\text { Criterion: Emotional } \\
\text { Deprivation }\end{array}$ & & \\
& 0.428 & $0.183^{* *}$ & $(-) 0.428^{* *}$ \\
$\begin{array}{l}\text { Model 1 } \\
\text { 1. Interpersonal Communication }\end{array}$ & 0.484 & $0.051^{*}$ & $(-) 0.475^{* *}$ \\
$\begin{array}{l}\text { Model 2 } \\
\text { 1. Interpersonal Communication }\end{array}$ & & & $0.23^{*}$ \\
2. Proaction & 0.525 & $0.041^{*}$ & $(-) 0.462^{* *}$ \\
$\begin{array}{l}\text { Model 3 } \\
\text { 1. Interpersonal Communication }\end{array}$ & & & $0.213^{*}$ \\
2. Proaction & & & $0.204^{*}$ \\
3. Flow & & $0.275^{*}$ & \\
Total R & & & \\
\hline
\end{tabular}

Note: ${ }^{*} \mathrm{p}<0.01 ;{ }^{*} \mathrm{p}<0.05, \mathrm{~N}=80, \beta=$ Standardized Beta Coefficient, $\mathrm{R}=$ co-efficient of correlation,

$\Delta \mathrm{R} 2=$ change in $\mathrm{R}$ squared

The contribution of Interpersonal Communication in predicting emotional deprivation was observed to be $18.3 \%$. Proaction dimension of Organizational Culture and the dimension of flow followed Interpersonal Communication in predicting emotional deprivation and contribute $5.1 \%$ and $4.1 \%$, respectively. The table further revealed that Interpersonal Communication was negatively correlated with emotional deprivation $(\beta=-0.428)$. It also revealed a positive relationship with proaction $(\beta=0.23)$ and flow ( $\beta=0.204)$.In other words it can be stated that direct face to face communication with immediate feedback is a major predictor of Emotional deprivation. It can also be inferred that taking initiative, preplanning and taking preventive action rather than reacting to situations and involving oneself in highly absorbing activity and recollecting our good experiences act as precursors to emotional deprivation. 
Table 4 - Stepwise regression analyses showing various models predicting Social companionship in employees working in Customer Service Relationship $(n=80)$.

\begin{tabular}{|c|c|c|c|}
\hline Predictor & $\mathrm{R}$ & $\Delta \mathrm{R}^{2}$ & $\beta$ \\
\hline & Criterion: Social & & \\
\hline & Companionship & & \\
\hline Model 1 & 0.467 & $0.218 * *$ & \\
\hline 1. Interpersonal Communication & & & $(-) 0.467 * *$ \\
\hline Model 2 & 0.526 & $0.059^{*}$ & \\
\hline 1. Interpersonal Communication & & & $(-) 0.666 * *$ \\
\hline 2. Self Expression & & & $0.314^{*}$ \\
\hline Model 3 & 0.565 & $0.042^{*}$ & \\
\hline 1. Interpersonal Communication & & & $(-) 0.714^{* *}$ \\
\hline 2. Self Expression & & & $0.322 *$ \\
\hline 3. Proaction & & & $0.21 *$ \\
\hline Model 4 & 0.595 & $0.035^{*}$ & \\
\hline 1. Interpersonal Communication & & & $(-) 0.615^{* *}$ \\
\hline 2. Self Expression & & & $0.289 *$ \\
\hline 3. Proaction & & & $0.303 *$ \\
\hline 4. Openness & & & $(-) 0.231 *$ \\
\hline Total $\mathrm{R}^{2}$ & & $0.354 *$ & \\
\hline
\end{tabular}

Note: **p $<0.01 ; * \mathrm{p}<0.05, \mathrm{~N}=80, \beta=$ Standardized Beta Coefficient, $\mathrm{R}=$ co-efficient of correlation,

$\Delta \mathrm{R}_{2}=$ change in $\mathrm{R}$ squared

Results, as presented in Table 4, indicated that Interpersonal Communication was a major predictor of social companionship. The contribution of Interpersonal Communication in predicting social companionship was 21.8\%. Proaction dimension of Organizational Culture, self expression dimension of Interpersonal Communication and openness dimension of Organizational Culture were then, predictors of social companionship and contribute $5.9 \%, 4.2 \%$ and $3.2 \%$ respectively. Table 4 further indicated a negative relationship between social companionship and Interpersonal Communication $(\beta=-0.467)$ and openness $(\beta=0.231)$ and a positive relationship with self expression $(\beta=0.314)$ and proaction $(\beta=$ 0.231). It can be inferred from Table 4 that face to face transactions with colleagues, superiors or subordinates, clarity in expressing one's own thoughts and ideas, taking initiatives at work and being spontaneous in expressing ideas and thoughts without being defensive about them predict social companionship at Workplace. 
Table 5 - Summary of stepwise regression, showing predictors for dimensions of Loneliness at Workplace: Emotional deprivation and Social companionship in Hotel Industry $(n=80)$.



Note: $* * \mathrm{p}<0.01 ; * \mathrm{p}<0.05, \mathrm{~N}=80$

Table 5 indicated a summary of the regression analyses for the emotional deprivation and social companionship dimensions of Loneliness at Workplace in the Hotel Industry. Emotional deprivation in employees of Hotel Industry was predicted by proaction dimension of Organizational Culture, rumination dimension of Dealing with Emotions, experimentation dimension of Organizational Culture, Interpersonal Communication and perceived acceptance dimension of Interpersonal Communication. Table 5, also indicated that social companionship in Hotel Industry employees was predicted by rumination dimension of Dealing with Emotions, experimentation dimension of Organizational Culture, clarity dimension of Interpersonal Communication and openness dimension of Organizational Culture. Tables 6 and 7 represent these dimensions in details. 
Table 6 - Stepwise regression analyses showing various models predicting Emotional deprivation in employees working in Hotel Industry $(n=80)$.

\begin{tabular}{lccc}
\hline \multicolumn{1}{c}{ Predictor } & \multicolumn{1}{c}{$\mathrm{R}$} & \multicolumn{1}{c}{$\Delta \mathrm{R}^{2}$} & \\
\hline & \multicolumn{1}{c}{ Criterion: Emotional Deprivation } \\
Model 1 & 0.459 & $0.211^{* *}$ & \\
1. Proaction & & & $(-) 0.459^{* *}$ \\
Model 2 & 0.591 & $0.139^{* *}$ & $(-) 0.433^{* *}$ \\
1. Proaction & & & $0.373^{* *}$ \\
2. Rumination & & & \\
Model 3 & 0.662 & $0.088^{* * *}$ & $(-) 0.309^{* *}$ \\
1. Proaction & & & $0.413^{* *}$ \\
2. Rumination & & & $(-) 0.323^{* *}$ \\
3. Experimentation & & & $(-) 0.263^{* *}$ \\
Model 4 & 0.700 & $0.052^{* *}$ & $0.411^{* *}$ \\
1. Proaction & & & $(-) 0.270^{* *}$ \\
2. Rumination & & $(-) 0.243^{* *}$ \\
3. Experimentation & & \\
4. Interpersonal Communication & & & $(-) 0.304^{* *}$ \\
Model 5 & 0.721 & $0.387^{* *}$ \\
1. Proaction & & $(-) 0.274^{* *}$ \\
2. Rumination & & $(-) 0.307^{* *}$ \\
3. Experimentation & & $0.193^{*}$ \\
4. Interpersonal Communication & & & 0.519 \\
5. Perceived Acceptance & & & \\
Total R & & & \\
\hline
\end{tabular}

Note: $* * \mathrm{p}<0.01 ; * \mathrm{p}<0.05, \mathrm{~N}=80, \beta=$ Standardized Beta Coefficient, $\mathrm{R}=$ co-efficient of correlation, $\Delta \mathrm{R} 2=$ change in $\mathrm{R}$ squared

Results, as presented in the table above, indicated that proaction was a major predictor of emotional deprivation. The contribution of proaction in predicting emotional deprivation was $21.1 \%$. The dimension of rumination, Organizational Culture dimension of experimentation, Interpersonal Communication and its dimension perceived acceptance follow proaction as predictors of emotional deprivation and contribute $13.9 \%, 8.8 \%, 5.2 \%$ and $2.9 \%$ respectively. The Table above revealed a negative relationship between emotional deprivation and proaction $(\beta=-0.459)$, experimentation $(\beta=-0.323)$ and Interpersonal Communication $(\beta=-0.243)$ and a positive relationship between emotional deprivation and rumination $(\beta$ $=0.373)$ and perceived acceptance $(\beta=0.193)$. This reflected that initiative-taking and preplanning, recalling our miseries, misfortunes and failures, using and encouraging innovative methods for solving problems at workplace, communicating directly with another employee and providing immediate feedback and perceptions of being accepted or rejected by others signify the presence of emotional deprivation. 
Table 7 - Stepwise regression analyses showing various models predicting Social companionship in employees working in Hotel Industry $(n=80)$.

\begin{tabular}{lccc}
\hline \multicolumn{1}{c}{ Predictor } & $\mathrm{R}$ & $\Delta \mathrm{R}^{2}$ & $\beta$ \\
\hline & $\begin{array}{l}\text { Criterion: Social } \\
\text { Companionship }\end{array}$ & & \\
Model 1 & 0.436 & $0.19^{* *}$ & \\
1. Experimentation & & & $(-) 0.436^{* *}$ \\
Model 2 & 0.531 & $0.092^{* *}$ & $(-) 0.465^{* *}$ \\
1. Experimentation & & & $0.305^{* *}$ \\
2. Rumination & 0.596 & $0.074^{* *}$ & \\
Model 3 & & & $(-) 0.435^{* *}$ \\
1. Experimentation & & & $0.323^{* *}$ \\
2. Rumination & & & $(-) 0.274^{* *}$ \\
3. Clarity & 0.624 & $0.033^{*}$ & $(-) 0.350^{* *}$ \\
Model 4 & & & $0.327^{* *}$ \\
1. Experimentation & & & $(-) 0.265^{* *}$ \\
2. Rumination & & & $(-) 0.202^{*}$ \\
3. Clarity & & & $0.389^{*}$ \\
4. Openness & & & \\
Total R & & & \\
\hline
\end{tabular}

Note: ${ }^{*} \mathrm{p}<0.01 ;{ }^{*}<<0.05, \mathrm{~N}=80, \beta=$ Standardized Beta Coefficient, $\mathrm{R}=$ co-efficient of correlation,

$\Delta \mathrm{R} 2=$ change in $\mathrm{R}$ squared

Results, as presented in the table above, indicated that experimentation dimension of Organizational Culture was a major predictor of social companionship. The contribution of experimentation in predicting social companionship was 19\%. The Dealing with Emotion dimension of rumination, clarity dimension of Interpersonal Communication and openness dimension of Organizational Culture followed experimentation as predictors of social companionship and contribute $9.2 \%, 7.4 \%$ and $3.3 \%$ respectively. Table 7 , disclosed that there was a negative relationship between social companionship and experimentation $(\beta=-0.436)$, clarity $(\beta=-0.274)$ and openness $(\beta=-0.202)$. The table also indicated a positive relationship between social companionship and rumination $(\beta=0.305)$. The reported results pointed towards the facts that taking a fresh perspective at things, encouraging creativity in approaching and solving problems, brooding and counting misfortunes and failures, ability to determine meaning, evoke explanation and work on the feedback provided and openly sharing ideas and thoughts and not being defensive about related suggestions predicts Social companionship

\section{DISCUSSION}

Stephen R. Covey (2014), the author of the famous book "The Seven Habits of Highly Effective People" quoted, "Employees first: Always treat your employees exactly how you want them to treat your best customers." Seen upon as one of the most efficient management-expert and motivational speaker, Covey always emphasized on employee engagement and growth in order to achieve the organizations goals and objectives. 
Working towards Covey's principle the objective of the present research endeavor was to study the differences between Day and Night Shift employees working in Customer Service and Hotel Industry. Differences in Work Setting and Work Shift were studied with respect to the dimensions of Organizational Culture; Interpersonal Communication and its dimensions; the dimensions of Dealing with Emotions and those of Loneliness at Workplace.

Corresponding results obtained through statistical analysis indicated that there was a significant difference between Day and Night Shift employees of Customer Service and Hotel Industry on the openness, trust, authenticity, collaboration and experimentation dimensions of Organizational Culture; the coping with feelings dimension of Interpersonal Communication; the rumination dimension of Dealing with Emotions and the emotional deprivation and social companionship dimensions of Loneliness at Workplace.

The reported findings regarding the significant differences on the dimensions of Organizational Culture coincides with the analysis that culture should not be treated as a unitary concept applying to all organizations. If treated as a unitary concept, the management is reducing the applicability of Organizational Culture as a critical tool for analysis (Martin, 1992; Ogbonna, \& Harris, 1998).Judge and Cable (1997) examined person-organization fit and subjective-fit of 182 job seekers and concluded that each seeker was attracted towards an organization depending on his or her perception of its Organizational Culture. Their findings do not only indicate towards a difference in Organizational Culture, they also point out that each job seeker seeks a job with a company whose values, ethics and actions coincide with their personality traits and their own system of values, ethics and actions.

The results reported a significant difference between Day and Night Shift employees on the coping with feelings dimension of Interpersonal Communication and the emotional deprivation dimension of Loneliness at Workplace. Both these dimensions can be understood against the theoretical concept of Emotional Labor advocated by Hochschild (1979). He defined Emotional Labor as "the process by which workers are expected to manage their feelings in accordance with organizationally defined rules and guidelines." The concept of Emotional Labor holds true for almost all employees in the Service sector. Smith-Coggins, Rosekind, Hurd and Buccino (1994) reported similar findings through their study on Physicians, who expressed to be generally happier when they were allowed to sleep during night hours and work during day hours. The reported findings also coincide with the findings of Bryson (2007) who propagates that with the 'Second Global Shift' and increase in off-shoring of Services a greater number of employees are required to become foreign by night and consequently play their oriental role in the day. This has led to increased experience of distanciated emotional labor in employees working in night shifts. This study by Bryson (2007) indicated that Night Shift employees experience a number of cognitive and emotional shifts. Thus, his study can be taken as a basis to understand a higher experience of emotional deprivation in Night Shift employees.

On one hand we focus on the direct effect of work shift on employee's emotions while on the other hand, Smith and Folkard (1993) focus on the effect of Work Shift on spouses of employees. They report that Work Shift impact the employee's relationships with their spouses who report to be unhappy with their shift work and remark about the substantial disruptions of Work Shift in their personal lives. This emotional pressure on employees also substantiates the finding of our present study.

Customer Service employees engage with a greater interaction with clients when compared to Hotel Industry employees. To this effect Wang, Liu, Liao, Gong, Kammeyer-Mueller and Shi (2013) reported a positive relationship between customer mistreatment and rumination in Customer Service employees. They also remarked that higher levels of rumination eventually culminated into a negative mood throughout the day. Zhan, Wang and Shi (2014) assessed this phenomenon further and bifurcated 
customer mistreatment into aggressive mistreatment and demanding mistreatment. Their findings reported that an employee's negative mood in the after math of his/her office hours was partly solidified in response to ruminative cognitions. It is also worthy to note that negative interactions are seen as predictors of a negative mood (Schuster, Kessler, \& Aseltine, 1990). These studies overlap with the finding of the current research paper which confirmed a significant difference between Customer Service and Hotel Industry employees with respect to the rumination dimension of Dealing with Emotions; with employees of Customer Service reporting a higher score on this dimension in comparison to the other group.

The results also confirmed a significant difference between employees of Customer Service and Hotel Industry on the social companionship dimension of Loneliness at Workplace. Employees working in Customer Service experience a higher level of social companionship when compared to employees working in Hotel Industry. Evidence to support this finding can be drawn from census regarding the number of employees working in both these industries. While a Customer Service industry like International Business Machines (IBM) reported having a world-wide employee base of 431,212 employees (IBM, 2013); Marriott Corporation a leading Hotel Industry reported having an employee base of 127,500 employees (Statista, 2015). Apart from these factual statistics from two organizations, Arun (2013) in an article in India Today reported that the Customer Service sector offers direct employment to about 1.98 million employees and indirect employment (e.g. security and transport) to about 7.5 million employees. Another dimension that differentiates a Hotel Industry from Customer Service is the number of departments and operational levels in a Hotel Industry. A Hotel Industry has three major departments namely: Front Desk, Housekeeping and Food and Beverages that function in complete independence from each other. These departments further function through smaller operational units (Gundersen, Heide, \& Olsson, 1996). This further segregates the Hotel Industry employees and as a result, they report lower social companionship within the organization.

Correspondingly, it was observed there was no significant difference between Day and Night Shift Customer Service and Hotel Industry employees on the confrontation, proaction and autonomy dimensions of organizational culture, interpersonal communication and its dimensions (apart from coping with feelings) and the flow dimension of dealing with emotions. These findings illustrated that the employees perceived their Organizational Culture as facing challenges and problems head-on instead of shying away from them. The employees agreed to be trained in 'putting up a front' instead of 'putting one's back' to the problem. Employees working in each setting and shift also perceived their top management to be proactive and not reactive. Employees believed that their Organization worked through pre-planning and calculative pay-offs. Back-ups and alternative methods were present as stand-by and the organizations always looked beyond immediate concern and planned for the long run. Moreover, the employees affirmed through their responses that their Organizational Culture extended freedom to the employees to plan and execute their actions in their own sphere. They were not bound by the Organization and this often promoted willingness in to take on responsibility, individual initiative and succession planning (Pareek \& Purohit, 2011).

In discussing the absence of a significant difference between employees on Interpersonal Communication and its dimensions we can view the article titled "How many calls should an outbound agent make?" byAdkins and Vernon (2010). The article pointed out that each Customer Service Agent spent between 55\% and 66\% (on an average) of his work time answering customer calls and resolving their queries and issues. While not answering calls, the employees either wait for the next call to arrive or are unavailable. On the other hand, as already discussed above, Gundersen, Heide, and Olsson (1996) pointed out that the Hotel Industry is divided into a number of departments and sub departments with each department having a small number of employees or having their employees strategically located and giving them little to no opportunity to meet and converse with each other. 
Results also indicated no significant differences between employees on the flow dimension of Dealing with Emotions. Each employee works in order to get appraised for his/her performance and contribute to the success of his/her organization and in terms of flow, it can be noted that employee satisfaction and positive attitude towards workplace, superiors and subordinates often leads to better organizational performance (Ostroff, 1992). Also recollecting good experiences, enjoying these recollections and engaging in highly absorbing activity (Pareek \& Purohit, 2011) motivates employees to perform better and move up the organizational hierarchy. Thus, it can be concluded that results of the present study support that employees working in both settings and shifts have clearly defined goals and objectives and aim towards achieving them.

Furthermore, the present paper also aimed to study whether the 8 dimensions of Organizational Culture (viz., openness, confrontation, trust, authenticity, proaction, autonomy, collaboration and experimentation); Interpersonal Communication and its 11 dimensions (viz., self disclosure, awareness, evaluation and acceptance of feedback, self expression, attention, coping with feelings, clarity, avoidance, dominance, handling differences and perceived acceptance) and the 2 dimensions of Rumination: Dealing with Feelings (viz., rumination and flow) predicted the 2 dimensions of Loneliness at Workplace (viz., social companionship and emotional deprivation).

The findings of this study bringto light that interpersonal communication predicts emotional deprivation in both customer service and hotel industry and social companionship in customer service. Interpersonal Communication is negatively correlated with emotional deprivation in the customer service and hotel industry. In other words, we can say that increase in face to face communication followed by immediate feedback often decreases an employee's feeling of distance with their colleagues. In their study, Moreland and Myaskovsky (2000) put forth that group performance improves remarkably when the group is trained together rather than trained apart from each other. Their training does not only provide them with a chance to communicate and interact with each other but also develops transactive memory and gives them a chance to learn about the skills of their other team members. In addition through a game-theoretical basis, Nasrallah, Levitt and Glynn (2003) demonstrate that a globally optimum communication regime set forth by the management in an organization improves the aggregate value and effectiveness of an organization. They also profess that this centrally dictated communication system has a single point of contact and the only way to move ahead is to involve all other employees and follow the set system.

On the contrary, the findings also recognized a negative relationship between social companionship and Interpersonal Communication in the Hotel Industry. One line of argument for this negative relationship can be drawn from the demographic data of the current research. While some participants in the study had a thorough educational background (Master's Degree) the others were not well educated $\left(10^{\text {th }}\right.$ and $12^{\text {th }}$ Standard) and this pattern was observed within some work-teams. This educational gap could be one of major cause for this inverse relationship. Another support to this current finding can be paralleled to 'Kitchen Violence.' A large population of the Hotel Industry employees is employed in the Food and Beverages Department and kitchen violence is described as being embedded in Chef's Working Culture (Johns \& Menzel, 1999). This form of bullying and negative non-verbal cues may also lead to the above presented inverse relationship.

The proaction dimension of Organizational Culture is also a major predictor of emotional deprivation in employees of Customer Service and Hotel Industry and social companionship in employees of Customer Service. Proaction is positively correlated with emotional deprivation and negatively correlated with social companionship among employees of Customer Service. In other words, it can be reiterated that an increase in taking initiative, preplanning and taking preventive action is accompanied by an increase in feelings of emotional distances between employees and a decrease in camaraderie and friendship at workplace. Another analysis that can be drawn from the same finding is that a decrease in 
taking initiative, preplanning and taking preventive action is accompanied by a decrease in feelings of emotional distances between employees and an increase in camaraderie and friendship at workplace. As illustrated in the Adkins and Vernon (2010) study, employees spend a major time on their job either answering a call or waiting for the next call. This study shows that these employees work individually rather than in a team and in being proactive and preparing for the next call, they often do not interact with other employees at work. It is also noted that most of the customer service employees undergo role stress as a result of the conflicting demands of the company, the supervisors and the customers (De Ruyter, Wetzels \& Feinberg, 2001).In managing the needs of all these elements proactively the employees work individually and thus experience high emotional deprivation and low social companionship.

Furthermore, the results indicated a negative relationship between proaction and emotional deprivation in employees working in the Hotel Industry. In other words, it can be explained that taking initiative, preplanning and taking preventive action decreases emotional deprivation in employees of Hotel Industry. Owen (2010) illustrated the Hotel Department Structure in the form of a flow chart. This chart brought to light that most of the Hotels work in groups and not individually, with the Management being split on different levels of functioning. Along this hierarchical line, Wiersema and Bantel (1992) propose the need for the Top Management to be proactive to overcome the initial inertia in the team. With the Top Management being proactive, team members feel free to communicate and share ideas and this eventually culminates into a strategic change in the Industry.

The openness dimension of organizational culture also emerged as another major predictor of social companionship in customer service and hotel industry. In further understanding, encouraging spontaneous expression of feelings andthoughts and also permitting employees to share these without defensiveness increases social companionship among employees in the customer service and on the contrary reduces social companionship among employees in hotel industry. The results further revealed a negative correlation between the Interpersonal Communication dimension of clarity and the dimension of social companionship. This indicated that an employee's ability to determine meaning, evoke explanation and work on feedback leads to reduced social companionship at workplace.

The history and emergence of the Customer Service and Hotel Industries can be used as a basis to support the above mentioned finding. The first ever global Customer Service can be traced back to 1950's. However Rockwell's (1973) firm, The Rockwell Galaxy is recognized to have executed the first most successful Customer Service program (Masey, Wright, Speas, Morell \& Freshwater, 2011). In India, the Customer Service is a more recent industry when compared to the world. On the other hand Andrew (2013) pointed out that the first hotel was established as early as the sixth century. Along this line of argument, we can conclude that Customer Service is an exceptionally new industry when compared to Hotel Industry and employees in the Customer Service (including managers) may be open to more ideas and exchanges. It is also observed that about $60 \%$ of the call center employees fall between the age ranges of 18 years to 34 years and thus may be seen as being more receptive to ideas and exchanges and discussing the same (Call Centre News, 2008) against their Hotel Industry counterparts who may not encourage spontaneous display of knowledge and emotions owing to their established system and greater age gap.

The experimentation dimension of organizational culture was identified as a predictor for emotional deprivation and social companionship among employees of the Hotel Industry. Experimentation was negatively correlated with both these dimensions of Loneliness at Workplace and thus we can conclude that the values of encouraging innovative approaches to solve problems, taking a fresh look at things and encouraging creativity are inversely related to emotional deprivation and social companionship. As explained above, Organizational Structure of the Hotel Industry is designed in the form of groups (Owen, 2010). Under this circumstance, one can note that the values, beliefs and attitudes of the Manager or Team Leader can have a profound impact on the employee and the team. This statement finds support in a 
study conducted by Wageman (2001) where he concluded that the leader's approach in designing his/her team and the quality of their coaching influences 'team self-management, the quality of member relationships, and member satisfaction.' Thus, it can be concluded that it is the attitude of the Manager towards the value of experimentation that either increases or decreases the feeling of emotional deprivation and social companionship among employees.

The results further revealed the rumination dimension of Dealing with Emotions as a predictor of emotional deprivation and social companionship among employees of the Hotel Industry. The dimension of rumination was positively correlated to emotional deprivation and social companionship and revealed that recalling one's miseries, misfortunes and failures was directly related to these dimensions. It is often a given in human behavior that individuals may react to a same situation differently. It is also seen that individuals who claim to be extremely happy are individuals who are unhappiest at other times (Brebner\& Martin, 1995). In addition, Pareek and Purohit(2011) point out, ruminators (i.e. individuals who ruminate) may either be optimistic or pessimistic. Optimistic ruminators are action-oriented while pessimistic ruminators are cynical and often complaining. These studies that draw attention towards the generalized characteristics of human behavior and difference between ruminators confirm that each individual reacts to a situation differently at a given point in time and thus they provide a strong basis for the identified positive relationship.

In further analysis, the flow dimension of Dealing with Emotions emerged as a predictor of emotional deprivation among employees of Customer Service. Results indicated a positive relationship between flow and emotional deprivation. In other words it can be concluded that involving oneself in highly absorbing activity and recollecting good experiences most of the time can lead to an increase in feelings of emotional deprivation. These positive feelings have often been studied in relation to risk-taking attitude. The Isen and Patrick (1983) study concluded that in both real and hypothetical situations participants who were elated and were experiencing positive affect either 'bet more' or took a 'longer shot' than their counter parts (who scored low on positive affect). This probability of taking a bet often varied with the 'object' of the bet. With the involvement of high-stakes, subjects (in whom positive affect had been induced) displayed a greater chance of winning in comparison to when the betting stakes were low (Isen \& Geva, 1987). Individuals who often display positive affect were also distinguished in achieving greater success in terms of their marriage, friendship, income, work performance and health while also reaping greater benefits from their organization (Lyubomirsky, King \& Diener, 2005). Against these findings, it can be concluded that an attitude towards high-end risk taking alongside being successful makes employees susceptible to emotional deprivation.

Additionally, the analysis revealed a positive relationship between the self expression dimension of Interpersonal Communication and social companionship dimension of Loneliness at Workplace among employees working in Customer Service. This finding implied that clarity in expressing one's own thoughts and ideas increases social companionship at workplace. Authentic communication and an ability to put forth an opinion is an indispensible quality of a great leader (Maxwell, 1999). Also, in order to be effective individual, one must become a role model for communication in the organization (Clutterbuck \&Hirst, 2002). To this effect it can be summarized that an individual with an ability to put forth an authentic opinion in an effective manner often garners the reputation of a leader and thus, is both acceptable and popular across the organization.

Further analysis revealed that the Interpersonal Communication dimensions of perceived acceptance and clarity are predictors of emotional deprivation and social companionship among the employees of Hotel Industry. The perceived acceptance was positively correlated with the dimension of emotional deprivation. This signified that an employee's perception of being accepted or rejected by others was 
positively related to the employee's feelings of emotional deprivation. The Attribution Theory popularized by Heider (1944) postulated that individuals measure the behaviors of other on the basis of external attribution and analyze their own cognitions and behaviors based on internal characteristics and traits. Thus, an increase in feelings of negative attribution to self can be cited as a perfect situation for an increase in feelings of emotional deprivation.

The theory, review of literature, selection of sample, method inculcated, analysis and arguments presented above lead to highlighting the following implications of the study.

\section{Implications}

The research study being discussed has a far reaching applicative value. It is the first study, to the researcher's knowledge that studies the effect of both the Work Setting and the Work Shift on the constructs of Organizational Culture, Interpersonal Communication, Dealing with Emotions and Loneliness at Workplace. Since, these phenomena were rather unrelated, the aim of the present study was to identify whether these constructs were related in any way and at any level. The research was motivated by the assumption that employees working in the Night Shift were at a greater risk of physiological, emotional and psychological breakdown. Accordingly, the results also indicated that employees working in either Work Setting and in either the Day or Night shift significantly differed on various dimension of Organizational Culture, Interpersonal Communication, Dealing with Emotions and Loneliness at Workplace.

The current research recommends other researchers to expand the model and identify other internal and external factors that pronounce Loneliness at Workplace. Also the findings of the current study can be used as a bench mark by the Management of an Organization towards identifying and developing a Culture that promotes social companionship and reduces emotional deprivation in its employees. Human Resource Specialist, Organizational Trainers and Organizational Psychologists can also use the findings of this study to design corresponding modules and train their employees in improved organizational communication skills and effective perception and treatment of one's emotions and feelings.

\section{REFERENCES}

1. Abu-Jarad, I. Y., Yusof, N. A., \&Nikbin, D. (2010).A review paper on organizational culture and organizational performance. International Journal of Business and Social Science, 1(3), 26-46.

2. Adkins, C. \& Vernon, D. (2010, March 14). How many calls should an outbound agent make? callcenterhelper.com. Retrieved from http://www.callcentrehelper.com/how-many-calls-should-anoutbound-agent-make-57157.htm.

3. Andrews, S. (2013). Hotel front office: a training manual. Tata McGraw-Hill Education.

4. Call Centre News. (2008, June 18). Callcenter helper.com.Retrieved from http://www.callcentrehelper.com/do-call-centres-discriminate -against-older-workers-1778.htm.

5. Arun M. G. (2013, March 15). Last Call.India Today in.Retrieved from http://indiatoday.intoday.in/story/bpo-industry-call-centre-culture-dying-in-india/1/258032.html

6. Ashkanasy, N. M. (2003). Emotions in organizations: A multilevel perspective. Research in multi-level issues, 2, 9-54.

7. Baars, C. W., \&Terruwe, A. A. A. (2002). Healing the unaffirmed: Recognizing emotional deprivation disorder. S. M. Baars,\& B. N. Shayne (Eds.). Alba House.

8. Bambacas, M., \&Patrickson, M. (2008).Interpersonal communication skills that enhance organisational commitment. Journal of Communication Management, 12(1), 51-72.

9. Barnard, C. I. (1968). The functions of the executive (Vol. 11). Harvard university press.

10. Barney, J. B. (1986). Organizational culture: can it be a source of sustained competitive advantage?. Academy of management review, 11(3), 656-665. 
11. Bienvenu, M. J. (1971). An interpersonal communication inventory. Journal of communication, 21(4), 381388.

12. Bolland, E., \& Lopes, C. (2014). Generations and Work. Palgrave Macmillan.

13. Boren, J. P. (2013). The relationships between co-rumination, social support, stress, and burnout among working adults. Management Communication Quarterly, 0893318913509283.

14. Brebner, J. M. T., \& Martin, M. (1995).Testing for stress and happiness: The role of personality factors. Stress and emotion: Anxiety, anger and curiosity, 15, 139-172.

15. Brink, A., \& Berndt, A. (2008). Relationship marketing and customer relationship management.Juta and Company Ltd.

16. Bryson, J. R. (2007). The 'second'global shift: The offshoring or global sourcing of corporate services and the rise of distanciated emotional labour. GeografiskaAnnaler: Series B, Human Geography, 89(s1), 31-43.

17. Chaffee, S. H., \& Berger, C. R. (1987). What communication scientists do.In C. R. Berger \& S. H. Chaffee (Eds.), Handbook of communication science (pp. 99-122). Newbury Park, CA: Sage

18. Chen, B. L., Mo, J. P., \& Wang, P. (2002).Market frictions, technology adoption and economic growth. Journal of Economic Dynamics and Control,26(11), 1927-1954.

19. Clutterbuck, D., \&Hirst, S. (2002). Leadership communication: A status report. Journal of communication Management, 6(4), 351-354.

20. Cooper, C. L., \& Robertson, I. T. (Eds.).(2004). International Review of Industrial and Organizational Psychology, 2004 (Vol. 19).John Wiley \& Sons.

21. Costa, G. (2003). Shift work and occupational medicine: an overview.Occupational Medicine, 53(2), 8388 .

22. Covey, S. R. (2014). The 7 habits of highly effective families.St. Martin's Press.

23. Csikszentmihalyi, M., \&Csikzentmihaly, M. (1991). Flow: The psychology of optimal experience (Vol. 41). New York: HarperPerennial.

24. De Ruyter, K. O., Wetzels, M., \& Feinberg, R. (2001). Role stress in call centers: Its effects on employee performance and satisfaction. Journal of interactive marketing, 15(2), 23-35.

25. Denison, D. R., \& Mishra, A. K. (1995). Toward a theory of organizational culture and effectiveness. Organization science, 6(2), 204-223.

26. Donahue, E. G., Forest, J., Vallerand, R. J., Lemyre, P. N., Crevier- Braud, L., \& Bergeron, É. (2012). Passion for work and emotional exhaustion: the mediating role of rumination and recovery. Applied Psychology: Health and Well- Being, 4(3), 341-368.

27. Fischer, K. W., Shaver, P. R., \&Carnochan, P. (1990). How emotions develop and how they organise development. Cognition and emotion, 4(2), 81-127.

28. Fyall, A. (2003). Collaborating for growth: The international hotel industry.

29. Graham, J. L. (1998). An analysis of sport managers' interpersonal communication skills in selected Ontario amateur sport organizations.

30. Gundersen, M. G., Heide, M., \& Olsson, U. H. (1996).Hotel guest satisfaction among business travelers. Cornell Hospitality Quarterly, 37(2), 72.

31. Haggard, D. L., Robert, C., \& Rose, A. J. (2011). Co-rumination in the workplace: Adjustment trade-offs for men and women who engage in excessive discussions of workplace problems. Journal of Business and Psychology, 26(1), 27-40.

32. Heider, F. (1944).Social perception and phenomenal causality. Psychological review, 51(6), 358.

33. Henderson, L. S. (1997). Toward a theory of managerial communication: the development of a conceptual and methodological framework. University Microfilms.

34. Hochschild, A. R. (1979). Emotion work, feeling rules, and social structure.American journal of sociology, 551-575.

35. Hofstede, G. (1980). Culture and organizations. International Studies of Management \& Organization, 10(4), 15-41.

36. IBM (2013).About IBM.Retrieved from http://www.ibm.com/ibm/in/en/.

37. Iftikhar, Z., Eriksson, I. V., \& Dickson, G. W. (2003).Developing an instrument for knowledge management project evaluation. Electronic Journal of Knowledge Management, 1(1), 55-62.

38. Isen, A. M., \&Geva, N. (1987). The influence of positive affect on acceptable level of risk: The person with a large canoe has a large worry. Organizational Behavior and Human Decision Processes, 39(2), 145-154.

39. Isen, A. M., \& Patrick, R. (1983). The effect of positive feelings on risk taking: When the chips are down. Organizational behavior and human performance, 31(2), 194-202. 
40. Ismail Al-Alawi, A., Yousif Al-Marzooqi, N., \&Fraidoon Mohammed, Y. (2007). Organizational culture and knowledge sharing: critical success factors. Journal of knowledge management, 11(2), 22-42.

41. Johns, N., \&Menzel, P. J. (1999). If you can't stand the heat!: Kitchen violence and culinary art. Hospitality Management, 18(2), 99-109.

42. Jones, P., \& Lockwood, A. (2002). The management of hotel operations. Cengage Learning EMEA.

43. Jones, R. A., Jimmieson, N. L., \& Griffiths, A. (2005). The impact of organizational culture and reshaping capabilities on change implementation success: The mediating role of readiness for change. Journal of Management Studies, 42(2), 361-386.

44. Judge, T. A., \& Cable, D. M. (1997).Applicant personality, organizational culture, and organization attraction. Personnel psychology, 50(2), 359-394.

45. Kondalkar, V. G. (2007). Organizational Behaviour. New Age International Publishers.

46. London, J. (2005). Generations at Work. Human Resource Institute.

47. Lyubomirsky, S., King, L., \&Diener, E. (2005). The benefits of frequent positive affect: does happiness lead to success?. Psychological bulletin,131(6), 803.

48. Major, V. S., Klein, K. J., \&Ehrhart, M. G. (2002). Work time, work interference with family, and psychological distress. Journal of applied psychology, 87(3), 427.

49. Martin, J. (1992). Cultures in organizations: Three perspectives. Oxford University Press.

50. Masey, D., Wright, P., Speas, D., Morell, S., \& Freshwater, B. (2011, January 19). The history of the call centre.callcenterhelper.com. Retrieved from http://www.callcentrehelper.com/ the-history-of-the-callcentre-15085.htm.

51. Maxwell, J. C. (1999). Twenty one indispensable qualities of a leader. Thomas Nelson Inc.

52. McMillan, E. (2002). Considering organisation structure and design from a complexity paradigm perspective. Tackling industrial complexity: the ideas that make a difference, 123-136.

53. Moreland, R. L., \&Myaskovsky, L. (2000). Exploring the performance benefits of group training: Transactive memory or improved communication?.Organizational behavior and human decision processes, 82(1), 117-133.

54. Nardi, B. A., \& Whittaker, S. (2002). The place of face-to-face communication in distributed work. Distributed work, 83-110.

55. Nasrallah, W., Levitt, R., \& Glynn, P. (2003). Interaction value analysis: When structured communication benefits organizations. Organization science, 14(5), 541-557.

56. Nolen-Hoeksema, S. (1998). The other end of the continuum: The costs of rumination. Psychological Inquiry, 9(3), 216-219.

57. Ogbonna, E., \& Harris, L. C. (1998). Organizational culture: It's not what you think. Journal of General Management, 23, 35-48.

58. O'Reilly, C. A., Chatman, J., \& Caldwell, D. F. (1991). People and organizational culture: A profile comparison approach to assessing person-organization fit. Academy of management journal, 34(3), 487516.

59. Ostroff, C. (1992). The relationship between satisfaction, attitudes, and performance: An organizational level analysis. Journal of applied psychology, 77(6), 963.

60. O'Toole, M. (2002).The relationship between employees' perceptions of safety and organizational culture. Journal of safety research, 33(2), 231-243.

61. Owen. (2013). Hotel Departmental Structure.Hotel Mule.Retrieved from http://www.hotelmule.com/forum/viewthread.php?tid=1555

62. Pareek, U., \&Purohit, S. (2011). Training Instruments in HRD and OD.McGraw Hill.

63. Peters, T. J., Waterman, R. H., \& Jones, I. (1982). In search of excellence: Lessons from America's best-run companies.

64. Pettigrew, A. M. (1979). On studying organizational cultures. Administrative science quarterly, 570-581.

65. Ren, H., Chen, Y., \& Liang Zhang, L. (2011).When you feel lonely at work: Social loneliness, work strains, and performance. In Global Business and Social Science Research Conference Beijing, China (pp. $1-21)$.

66. Robbins, S., Judge, T. A., Millett, B., \& Boyle, M. (2013). Organisational behaviour.Pearson Higher Education AU.

67. Roberts, K. H., \&O'reilly, C. A. (1974). Failures in upward communication in organizations: Three possible culprits. Academy of Management Journal,17(2), 205-215.

68. Rubin, R. B., \& Rubin, A. M. (1992).Antecedents of interpersonal communication motivation. Communication Quarterly, 40(3), 305-317. 
69. Salanova, M., Bakker, A. B., \&Llorens, S. (2006). Flow at work: evidence for an upward spiral of personal and organizational resources*. Journal of Happiness Studies, 7(1), 1-22.

70. Schuster, T. L., Kessler, R. C., \&Aseltine Jr, R. H. (1990). Supportive interactions, negative interactions, and depressed mood. American journal of community psychology, 18(3), 423-438.

71. Sheridan, J. E. (1992). Organizational culture and employee retention.Academy of management Journal, 35(5), 1036-1056.

72. Smith, L., \&Folkard, S. (1993). The perceptions and feelings of shiftworkers' partners. Ergonomics, 36(13), 299-305.

73. Smith-Coggins, R., Rosekind, M. R., Hurd, S., \& Buccino, K. R. (1994).Relationship of day versus night sleep to physician performance and mood. Annals of emergency medicine, 24(5), 928-934.

74. Statista (2015).Number of Marriott International employees worldwide from 2007 to 2015 (in thousands)*. The Statistics Portal.Retrieved from http://www.statista.com/statistics /297269/number-of-marriottinternational-employees-worldwide/

75. Steers, R. M., \& Black, J. S. (1994).Organizational behavior(5th ed.). New York, NY: Harper Collins.

76. Thomas, G. F., Zolin, R., \& Hartman, J. L. (2009). The central role of communication in developing trust and its effects on employee involvement.Journal of Business Communication.

77. Tobert, S., \& Moneta, G. B. (2013). Flow as a Function of Affect and Coping in the Workplace. Individual Differences Research, 11(3).

78. Wageman, R. (2001). How leaders foster self-managing team effectiveness: Design choices versus handson coaching. Organization Science, 12(5), 559-577.

79. Wang, M., Liu, S., Liao, H., Gong, Y., Kammeyer-Mueller, J., \& Shi, J. (2013).Can't get it out of my mind: Employee rumination after customer mistreatment and negative mood in the next morning. Journal of Applied Psychology, 98(6), 989.

80. WebFinance Incorporation (2016).BusineesDictionary.com, available online on http://www.businessdictionary.com/article/aboutus/

81. Wiersema, M. F., \&Bantel, K. A. (1992). Top management team demography and corporate strategic change. Academy of Management journal, 35(1), 91-121.

82. Wright, S. L., Burt, C. D., \& Strongman, K. T. (2006). Loneliness in the workplace: Construct definition and scale development.

83. Yilmaz, E. (2008). Organizational commitment and loneliness and life satisfaction levels of school principals. Social Behavior and Personality: an international journal, 36(8), 1085-1096.

84. Yilmaz, E. (2011). An investigation of teachers loneliness in the workplace in terms of human values they possess. African Journal of Business Management, 5(13), 5070-5075.

85. Zhan, Y., Wang, M., \& Shi, J. (2014).Lagged influences of customer mistreatment on employee mood: Moderating roles of maladaptive emotion regulation strategies. Individual Sources, Dynamics, and Expressions of Emotion (Research on Emotion in Organizations, Volume 9) Emerald Group Publishing Limited, 9, 203-224. 